\title{
Withdrawal from Chronic Phencyclidine Treatment Induces Long-Lasting Depression in Brain Reward Function
}

\author{
Cecile Spielewoy ${ }^{1,2}$ and Athina Markou*,1 \\ 'Department of Neuropharmacology, The Scripps Research Institute, La Jolla, CA, USA
}

\begin{abstract}
Phencyclidine (PCP) is a drug of abuse that has rewarding and dysphoric effects in humans. The complex actions of PCP, and PCP withdrawal in particular, on brain reward function remain unclear. The purpose of the present study was to characterize the effects of withdrawal from acute and chronic PCP treatment on brain reward function in rats. A brain stimulation reward procedure was used to evaluate the effects of acute PCP injection $(0,5$, or $10 \mathrm{mg} / \mathrm{kg})$ or chronic PCP treatment $(0,10$, 15 , or $20 \mathrm{mg} / \mathrm{kg} /$ day for 14 days delivered via subcutaneous osmotic minipumps) on brain reward function. Withdrawal from acute administration of 5 and $10 \mathrm{mg} / \mathrm{kg}$ PCP produced a decrease in brain reward function as indicated by a sustained elevation in brain reward thresholds. When administered chronically, 10 , 15 , or $20 \mathrm{mg} / \mathrm{kg} /$ day PCP induced a progressive dose-dependent potentiation of brain stimulation reward, while cessation of the treatment resulted in significant elevations in reward thresholds reflecting diminished reward. Specifically, withdrawal from 15 or 20 mg/ $\mathrm{kg} /$ day PCP induced a depression in brain reward function that lasted for the entire month of observation. These results indicate that prolonged continuous administration of high PCP doses facilitates brain stimulation reward, while withdrawal from acute high PCP doses or chronic PCP treatment results in a protracted depression of brain reward function that may be analogous to the dysphoric and anhedonic symptoms observed in PCP dependence, depression, and schizophrenia.

Neuropsychopharmacology (2003) 28, I I06-I I |6, advance online publication, 26 March 2003; doi: I 0. I038/sj.npp. I 300 I 24
\end{abstract}

Keywords: brain stimulation reward; thresholds; phencyclidine; withdrawal; depression; negative symptoms of schizophrenia; rat

\section{INTRODUCTION}

Phencyclidine (PCP), a noncompetitive antagonist of ionotropic $N$-methyl-D-aspartate (NMDA) glutamate receptors, is a psychotomimetic drug that is abused by humans because of its rewarding and hallucinogenic properties (Crider, 1986; Fram and Stone, 1986). Rodents appear to be less sensitive to the reinforcing properties of PCP than to those of other drugs abused by humans as indicated by the fact that rodents do not self-administer PCP at the same rates as they self-administer opiate or psychostimulant drugs (Collins et al, 1984), avoid an environment previously associated with the effects of PCP (Barr et al, 1985; Iwamoto, 1986; Kitaichi et al, 1999), and often need 'priming' PCP injections to initiate PCP self-administration or PCP-induced place preference (Wise, 1989; Noda et al, 1998). The rewarding effects of PCP can be evaluated also in

\footnotetext{
*Correspondence: Dr A Markou, Department of Neuropharmacology, CVN-7, The Scripps Research Institute, 10550 North Torrey Pines Road, La Jolla, CA 92037, USA, Tel: + I 858784 7244, Fax: + I 858784 7405, E-mail: amarkou@scripps.edu

${ }^{2}$ Present Address: Picower Center for Learning \& Memory, Massachusetts Institute of Technology, Cambridge, MA 02139-4307, USA.

Received 04 June 2002; revised II September 2002; accepted 13 September 2002

Online publication: 17 September 2002 at http://www.acnp.org/ Citations/Npp091702383
}

rodents using the intracranial self-stimulation (ICSS) paradigm. Systemic (Wise et al, 1992; Bespalov et al, 1999) or intracerebral injections of the drug directly into the nucleus accumbens shell (Carlezon and Wise, 1996a, b) have been shown to either lower the threshold for brain stimulation reward (Kornetsky et al, 1979) or increase the rate at which rodents will lever press at fixed stimulation parameters (Schaefer and Michael, 1990). Studies investigating the neurobiological mechanisms sustaining the reward facilitating effect of PCP on brain reward function reported that both the action of the drug as a dopamine reuptake inhibitor and as an NMDA receptor antagonist (Smith et al, 1977; Gerhardt et al, 1987; Rothman et al, 1989; Kuhar et al, 1990) are each sufficient in mediating reward-related effects in the nucleus accumbens (eg Carlezon and Wise, 1993, 1996a; however Carlezon and Wise, 1996b).

By contrast, little work has focused on the negative affective aspects of PCP withdrawal reflected by diminution of brain stimulation reward. In humans, it is well documented that withdrawal from many different drugs of abuse, including PCP, triggers a depressive mood, characterized by an 'inability to experience pleasure' (American Psychiatric Association, 1994). An operational measure of this deficit in animals is the elevation in brain reward threshold observed during drug withdrawal that reflects diminished interest of the subjects in the rewarding 
electrical stimuli (Geyer and Markou, 1995). A deficit in brain reward function has been reported during withdrawal from amphetamine (eg Leith and Barrett, 1976; Kokkinidis and Zacharko, 1980; Kokkinidis et al, 1986; Lin et al, 1999; Paterson et al, 2000), cocaine (Markou and Koob, 1991, 1992a; Baldo et al, 1999), opiates (Schulteis et al, 1994), ethanol (Schulteis et al, 1995), and nicotine (Epping-Jordan et al, 1998; Harrison et al, 2001). The aim of the present study was to characterize in rats the effects on brain stimulation reward of withdrawal from different PCP treatments. We hypothesized that, like withdrawal from other drugs of abuse, the cessation of PCP treatment will produce in rats a decrease in brain reward function that will reflect a deficit in experiencing pleasure.

As hypothesized previously (Markou et al, 1998; Harrison et al, 2001; Markou and Kenny, 2002), elevations in brain reward thresholds associated with withdrawal from drugs of abuse may be homologous, or at least analogous, to the symptom of 'diminished interest or pleasure' (ie anhedonia) characterizing nondrug-induced depressions (American Psychiatric Association, 1994). Further it has been hypothesized that the negative symptoms of schizophrenia, such as anhedonia and avolition (ie lack of motivation; American Psychiatric Association, 1994) may be neurobiologically similar to depressive symptomatology, such as anhedonia and dysphoria, seen in both drug- and nondrug-induced depressions (Markou and Kenny, 2002). Withdrawal from PCP treatment induces in humans and rodents some longlasting behavioral and neurochemical perturbations that have been hypothesized to have relevance to schizophrenia symptomatology and neuropathologies, respectively (Jentsch and Roth, 1999). These observations have led to the hypothesis of hypofunctioning of the glutamatergic system as one of the pathophysiologies mediating schizophrenia (Javitt and Zukin, 1991; Carlsson et al, 2001). The purpose of the present study was to test the hypothesis that withdrawal from PCP administration results in elevations in brain reward thresholds. We propose here that such potential elevations in brain reward thresholds induced by PCP withdrawal would reflect an anhedonic state that may be analogous to the symptom of anhedonia that is seen in depression, and which is also one of the negative symptoms of schizophrenia. Our hypothesis is that this common symptom of anhedonia seen in different psychiatric disorders may be mediated by overlapping neurobiological mechanisms (Markou et al, 1998; Markou and Kenny, 2002).

In the present studies, two different drug administration regimens were used. Acute bolus injections of high PCP doses (5 and $10 \mathrm{mg} / \mathrm{kg}$ ) were administered to the animals and then brain stimulation reward thresholds were examined $8-48 \mathrm{~h}$ after PCP administration. Pharmacokinetic findings indicated that after a bolus injection of $5 \mathrm{mg} / \mathrm{kg}$ PCP, PCP levels in the brain rise and drop rapidly during the first $2 \mathrm{~h}$, and at $8 \mathrm{~h}$ postinjection PCP is no longer detectable (eg Schroeder et al, 1998). Thus, it is assumed that the behavioral evaluations performed here assessed the effects of withdrawal from PCP on reward thresholds. These time points also correspond to the time of occurrence of transient pathomorphological changes induced by the drug in specific cortical subregions of the brain (Corso et al, 1997), thereby allowing an evaluation of the possible consequences of the neurotoxic effects of PCP on brain reward thresholds (see Discussion).

Then, we examined the effects of chronic treatment with 10,15 , or $20 \mathrm{mg} / \mathrm{kg} /$ day PCP administered continuously for 14 days and the effects of cessation of PCP administration on brain reward function. It has been reported that there are qualitative and quantitative differences in the effects of acute vs chronic PCP exposure (Jentsch and Roth, 1999). For example, studies demonstrated that the chronic treatment selected here has been effective previously in inducing durable cognitive dysfunction, social withdrawal, and enhancement of immobility time in the forced swim test in rats or mice that are not observable after acute PCP (Noda et al, 1995, 2000; Jentsch et al, 1997c; Quiao et al, 2001). Thus, it was important to characterize withdrawal from both high-dose bolus PCP administration and withdrawal from chronic sustained PCP exposure in the ICSS paradigm. Moreover, because the behavioral and neurochemical effects induced by withdrawal from chronic PCP treatment have been shown to be surprisingly long lasting, the argument has been made that withdrawal from chronic PCP exposure is likely to mimic the psychopathologies and neuropathologies associated with schizophrenia (Jentsch and Roth, 1999). Therefore, we tested the long-lasting effect of withdrawal from chronic PCP treatment on brain reward function in the context of its relevance to the anhedonia reported in the symptomatology of both schizophrenia and depression.

\section{MATERIALS AND METHODS}

\section{Subjects}

Male Wistar rats (Charles River, Raleigh, NJ), weighing 330$350 \mathrm{~g}$ at the beginning of the experiments, were housed in pairs in a temperature- and humidity-controlled environment with a reversed $12 \mathrm{~h}$ light/dark cycle (lights off at 10:00 am). Food and water were available ad libitum. After arrival, animals were allowed a week to habituate to the vivarium; during this period, rats were handled twice to familiarize them to the experimenter and to handling. All subjects were treated in accordance with the National Institutes of Health Guide for the Care and Use of Laboratory Animals, and the facilities and experimental protocols were in accordance with the Association for the Assessment and Accreditation of Laboratory Animal Care of the Scripps Research Institute. All testing was conducted during the dark phase of the light/dark cycle, unless otherwise stated.

\section{Apparatus}

The experimental apparatus consisted of 16 Plexiglas chambers $\left(30.5 \times 30 \times 17 \mathrm{~cm}^{3}\right) \quad$ (Med Associates Inc., St Albans, VT) encased in sound-attenuating boxes (San Diego Instruments, San Diego, CA). Each operant chamber contained a stainless-steel grid floor and a metal wheel manipulandum centered in a sidewall, which required $0.2 \mathrm{~N}$ force to rotate it a quarter turn. Subjects were connected to the stimulation circuit by bipolar leads (Plastics One, Roanoke, VA) attached to gold-contact swivel commutators (model SL2C, Plastics One, Roanoke, VA). Brain stimulation 
was delivered by constant current stimulators (Stimtech 1200, San Diego Instruments, San Diego, CA). The stimulation parameters, data collection, and all test session functions were controlled by a microcomputer.

\section{Surgical Procedures}

ICSS electrode implantation. Subjects were anesthetized with a halothane/oxygen vapor mixture (1.0-1.5\%) and placed in a stereotaxic frame (David Kopf Instruments, Tujunga, CA). Stainless-steel bipolar electrodes (model MS303/2, Plastics One, Roanoke, VA), cut to a length of $11 \mathrm{~mm}$, were implanted in the posterior lateral hypothalamus (AP $-0.5 \mathrm{~mm}$ from bregma, $\mathrm{ML} \pm 1.7 \mathrm{~mm}, \mathrm{DV}$ $-8.3 \mathrm{~mm}$ from dura, with the incisor bar $5 \mathrm{~mm}$ above the interaural line (Pellegrino et al, 1979)). Half of the animals were prepared with the electrodes on the right side and the remainder on the left side of the brain, to counterbalance any possible brain asymmetries (Glick et al, 1980; Markou and Frank, 1987). Dental acrylic was applied around the base of the electrode and four stainless-steel screws (inserted into the skull) to fix the assembly permanently to the skull. All animals were allowed to recover for at least 7 days prior to any behavioral testing.

Osmotic minipump implantation and removal. Rats were anesthetized with a halothane/oxygen vapor mixture (1.0$1.5 \%$ ), and an osmotic minipump (model 2ML2 (14-day), Alza Corp, Palo Alto, CA) was inserted subcutaneously (s.c.) (back of the animal parallel to the spine) with the flowmoderator directed posteriorly. The wound was stapled, and an antibacterial preparation was applied to the incision area. The rats were retested on the ICSS task $24 \mathrm{~h}$ after the minipump implantation. On day 14, the pumps were surgically removed under halothane anesthesia and the animals were allowed a period of $6 \mathrm{~h}$ to recover before any behavioral testing.

\section{Drugs}

d-PCP sulfate (obtained from the National Institute on Drug Abuse, Bethesda, MD) was dissolved in $0.9 \%$ saline sterile solution and administered s.c. in a volume of $1 \mathrm{ml} / \mathrm{kg}$ body weight or via subcutaneous osmotic minipumps.

\section{ICSS Behavioral Procedure}

The ICSS task used is a modified version (Markou and Koob, 1992b, 1993) of a discrete-trial current-threshold procedure originally developed by Kornetsky et al (1979, 1981). The apparatus, surgery, procedure, and parameters for the lateral hypothalamic ICSS task have been described in detail previously (Kornetsky et al, 1979, 1981; Markou and Koob, 1992b, 1993).

The subjects were trained initially to turn the wheel manipulandum on a fixed ratio 1 (FR1) schedule of reinforcement. Each quarter turn of the wheel resulted in the delivery of a $500 \mathrm{~ms}$ train of $0.1 \mathrm{~ms}$ cathodal squarewave pulses at a frequency of $100 \mathrm{~Hz}$. After the successful acquisition of responding for stimulation on this FR1 schedule, defined as 100 reinforcements within $10 \mathrm{~min}$, the rats were trained gradually on the discrete-trial current- threshold procedure (Kornetsky et al, 1979, 1981; Markou and Koob, 1992b, 1993).

Each trial began with the delivery of a noncontingent electrical stimulus, followed by a $7.5 \mathrm{~s}$ response window within which the subject could make a response to receive a second contingent stimulus identical to the initial noncontingent stimulus. A response during this time window was labeled a positive response, while the lack of a response was labeled a negative response. During a $2 \mathrm{~s}$ period immediately after a positive response, additional responses had no consequences. The intertrial interval (ITI) that followed either a positive response or the end of the response window (in the case of a negative response) had an average duration of $10 \mathrm{~s}$ (ranging from 7.5 to $12.5 \mathrm{~s}$ ). Responses that occurred during the ITI resulted in a further $12.5 \mathrm{~s}$ delay of the onset of the next trial. During training on the discrete-trial procedure, the duration of the ITI and delay periods induced by inappropriate responses occuring during the ITI were gradually increased until animals performed consistently for a fixed stimulation intensity at standard test parameters. The animals were subsequently tested on the current-threshold procedure in which stimulation intensities were varied according to the classical psychophysical method of limits (Engen, 1971). A test session consisted of four alternating series of descending and ascending current intensities starting with a descending series. Blocks of three trials were presented to the subject at a given stimulation intensity, and the intensity changed by steps of $5 \mu \mathrm{A}$ between blocks of trials. The initial stimulus intensity was set at approximately $40 \mu \mathrm{A}$ above the baseline current threshold for each animal. Each test session typically lasted 30-40 min and provided two dependent variables for behavioral assessment: threshold and response latency. Before any drug administration, rats were tested using the above brain stimulation procedure until stable baseline thresholds and latencies were achieved $( \pm 10 \%$ over a 5-day period), which typically occurred after 2-3 weeks of daily baseline testing. Each ICSS test session was approximately $30 \mathrm{~min}$ long and provided two behavioral measures defined as follows:

Brain reward thresholds. The current threshold for each descending series was defined as the stimulus intensity between the successful completion of a block of trials (positive responses during two or more of the three trials) and the stimulus intensity for the first block of trials, of two consecutive blocks, during which the animal failed to respond positively on two or more of the three trials. During the ascending series, the threshold was defined as the stimulus intensity between the unsuccessful completion of a block of trials (negative responses during two or more of the three trials) and the stimulus intensity for the first block of trials, of two consecutive blocks, during which the animal responded positively on two or more of the trials. Thus, during each test session, four thresholds were determined and the mean of these values was taken as the brain reward threshold for the session.

Response latency. The latency between the onset of the noncontingent stimulus at the start of each trial and a positive response was recorded as the response latency. The response latency for each test session was defined as the 
mean response latency of all trials during which a positive response occurred. Changes in response latencies reflect changes in the speed of responding that may be influenced by a variety of mechanisms, such as changes in motor performance and/or attention (Markou and Koob, 1991, $1992 b, 1993)$. Changes in the sensitivity of the reward pathway mediating ICSS reward do not affect response latencies (Markou and Koob, 1991, 1992b, 1993).

\section{Experiment 1: Effects of Withdrawal from Acute High Doses of PCP on Brain Stimulation Reward}

After establishment of stable baseline performance (less than $10 \%$ variation over 5 days), the animals were administered PCP or saline s.c. according to the following dose order that was the same for all rats: 0.0, 5.0, and $10.0 \mathrm{mg} / \mathrm{kg}$ PCP. This dose order was selected to prevent the highest PCP dose used in the study to result in permanent behavioral changes; thus it was desirable to administer the highest PCP dose last. ICSS tests were performed at 8 and $12 \mathrm{~h}$ after PCP administration and at 24-h intervals thereafter. These time points were selected based on preliminary unpublished data obtained in the authors' laboratory showing that ICSS testing performed prior to the $8 \mathrm{~h}$ time point is compromised by motoric performance inabilities because of the ataxia and stereotypy induced by PCP. Furthermore, pharmacokinetic findings indicate that $8 \mathrm{~h}$ after a bolus injection of $5 \mathrm{mg} / \mathrm{kg}$ PCP, the drug is no longer detectable in the brain of the subject (Schroeder et al, 1998). Consequently, the ICSS testing performed in the present experiment evaluated the effect on brain stimulation reward after withdrawal from acute PCP treatment. The animals were habituated to the injection procedure by administering saline on random days during the baseline period. Drug doses were administered at a minimal interval of 1 week, thus allowing at least 7 drug-free days between doses. All animals $(n=16)$ were drug naive at the beginning of the experiment and weighed two to three times per week.

\section{Experiment 2: Effects of Chronic PCP Treatment and PCP Withdrawal on Brain Stimulation Reward}

After stable self-stimulation performance had been achieved (less than $10 \%$ variation over 5 consecutive days), naïve animals were assigned to one of four treatment groups: 0.0 $(n=14), 10.0(n=14), 15.0(n=12)$, or $20.0(n=12) \mathrm{mg} / \mathrm{kg} /$ day PCP administered via subcutaneous 14-day osmotic minipumps. Rats were assigned to groups so that the groups' 5-day mean baseline thresholds were equal before any drug administration. The concentrations of PCP were adjusted to compensate for differences in body weight at the time of implantation. These doses of PCP and length of treatment were selected based on preliminary unpublished data obtained by the authors, showing that lower doses of PCP (ie 2.5 or $5 \mathrm{mg} / \mathrm{kg}$ ) delivered during a shorter period of time (ie via 7-day osmotic minipumps) induced only brief transient changes in brain stimulation reward thresholds. ICSS behavior and the body weight of the animals were assessed $24 \mathrm{~h}$ after minipump implantation and at 24-h intervals thereafter until pump removal on day 14 .

On day 14, first rats were tested on the ICSS task. Immediately after this ICSS session, the pumps were removed. Then, ICSS behavior was assessed at 6 and $12 \mathrm{~h}$ after removal of the pumps, and at 24-h intervals thereafter for the following 13 days (ie days 1-14 of withdrawal) and every second day for the following 14 days (ie days 15-30 of withdrawal). Body weight was measured immediately after each ICSS session. All testing and surgery occurred during the dark phase of the light/dark cycle, with the exception of the 12-h time point after removal of the pumps that, given the experimental schedule, was performed $2 \mathrm{~h}$ after the beginning of the light cycle (ie 12:00 am).

\section{Data Analyses}

Threshold and response latency data were expressed as a percentage of the mean baseline values assessed during 5 days before each PCP/vehicle injection or prior to the implantation of the minipumps. In addition, the average threshold for the withdrawal period was calculated by adding the threshold values over the indicated period of time (ie testing points after the cessation of administration of PCP or saline) and dividing by the number of testing points. All data were analyzed using the appropriate analyses of variance (ANOVAs) with factors defined as within- or between-subjects in accordance with the experimental design. Further, an ANOVA assessed the stability of the threshold and response latency baseline values throughout experiment 1; these analyses were performed on the raw threshold and latency values. Statistically significant main and interaction effects were followed by post hoc NewmanKeuls or Fisher's LSD tests. The level of significance was set at $p<0.05$.

\section{RESULTS}

\section{Experiment 1: Effects of Withdrawal from Acute High Doses of PCP on Brain Stimulation Reward}

Mean raw baseline values for brain reward thresholds or response latencies assessed before each PCP or vehicle injection ranged from 160.24 to $160.53 \mu \mathrm{A}$, and from 3.28 to $3.34 \mathrm{~s}$, respectively. There were no statistically significant differences between these baseline values for brain reward thresholds and response latencies indicating that the repeated treatment procedure did not alter baseline performance $(p>0.05)$. Withdrawal from acute injection of 5 or $10 \mathrm{mg} / \mathrm{kg}$ PCP elevated brain reward thresholds compared to thresholds after saline treatment (main effect of Drug: $F(2,45)=6.34, p<0.01)$, and this effect persisted up to $24 \mathrm{~h}$ after drug administration (main effect of Time: $\mathrm{F}(3,135)=17.12, p<0.0001) \quad$ (Figure 1a). There was no statistically significant Dose $\times$ Time interaction $(\mathrm{F}(6,135)=1.55$, NS). The two-way ANOVA performed on the response latency data revealed no main effect of Drug $(\mathrm{F}(2,45)=1.52$, NS), but a significant Time effect $(\mathrm{F}(3,135)=7.27, \quad p<0.0001)$, and a significant Treatment $\times$ Time interaction $(\mathrm{F}(6,135)=3.10, p<0.01)$. Post hoc analyses indicated that $10 \mathrm{mg} / \mathrm{kg}$ PCP significantly increased response latencies $8 \mathrm{~h}$ after the injection compared to latencies of control animals, while administration of $5 \mathrm{mg} / \mathrm{kg}$ PCP did not affect the latency to respond at any time point (Figure 1b). 

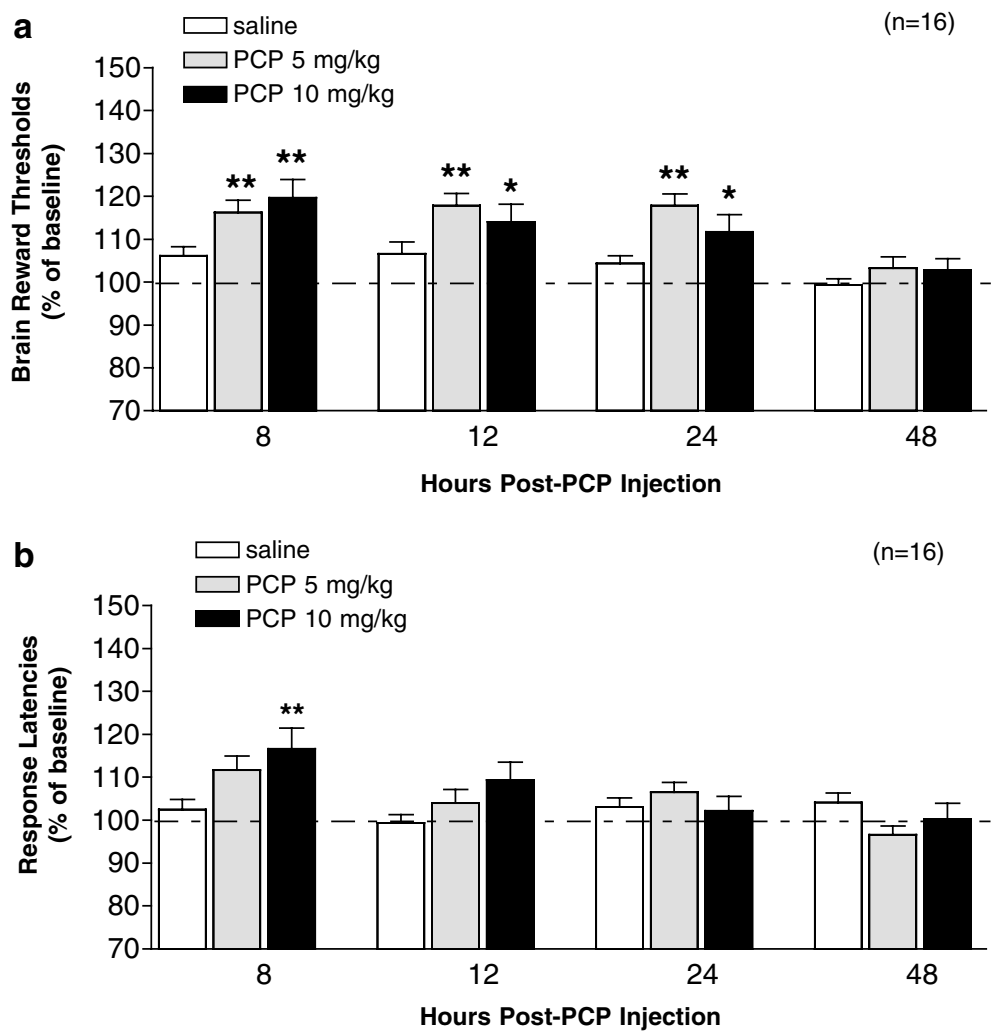

Figure I The long-term effects of acute high doses of PCP on brain reward thresholds and response latencies (mean \pm SEM). Brain reward thresholds (original values in $\mu \mathrm{A}$ reported here as percent of baseline) were elevated at 8,12 , and $24 \mathrm{~h}$ after PCP administration compared to those of saline-treated control animals (a); at the same time points there were no changes in response latencies (original values in seconds reported here as percent of baseline) except for the $10 \mathrm{mg} / \mathrm{kg}$ PCP group at the 8-h time point (b). Asterisks indicate statistically significant differences between the PCP and saline groups for specific time points ( $P p<0.05$ and $* * * 0.01$; Newman-Keuls post hoc test).

\section{Experiment 2: Effects of Chronic PCP Treatment and PCP Withdrawal on Brain Stimulation Reward}

The mean raw baseline values for brain reward thresholds or response latencies before implantation of the minipumps ranged from 105.00 to $135.83 \mu \mathrm{A}$, and from 3.29 to $3.47 \mathrm{~s}$, respectively. No statistically significant differences between the mean baseline thresholds or response latencies of subjects assigned to the saline-treated group and subjects assigned to each of the PCP-treated group were seen before the drug manipulation $(p>0.05)$, because animals were assigned to groups so that baseline group means were almost equal. Data for the PCP/vehicle exposure period when the osmotic minipumps were in the animals were analyzed separately from the data during the withdrawal period after the removal of the minipumps. During the 14day exposure to PCP, rats treated with PCP showed a significant progressive lowering of brain reward thresholds compared to thresholds of control animals prepared with saline-containing minipumps (Treatment effect: $\mathrm{F}(3,48)=3.83, \quad p<0.05 ; \quad$ Time effect: $\mathrm{F}(13,624)=9.29$, $p<0.0001$ ) (Figure 2a-c). However, there was no significant Treatment $\times$ Time interaction $(\mathrm{F}(39,624)=1.28$, NS), indicating that the three doses of PCP did not induce significantly different actions on brain reward thresholds during the chronic treatment. Removal of the minipumps induced significant treatment $(\mathrm{F}(3,48)=4.11, p<0.05)$ and time-dependent $(\mathrm{F}(23,1104)=13.22, p<0.0001)$ elevations in brain reward thresholds in the animals previously treated with PCP compared to control rats treated with saline. Most importantly, a significant Treatment $\times$ Time interaction $(\mathrm{F}(69,1104)=1.88, p<0.0001)$ showed that over 1 month of observation, withdrawal from chronic 10,15 , or $20 \mathrm{mg} /$ $\mathrm{kg}$ /day PCP affected brain reward thresholds differentially (Figure 2a-c). Post hoc comparisons showed that withdrawal from a 14-day exposure to 10 or $20 \mathrm{mg} / \mathrm{kg} / \mathrm{day}$ PCP significantly elevated brain reward thresholds to 12 and $24 \mathrm{~h}$ or 6,12 , and $24 \mathrm{~h}$, respectively, after cessation of the treatment (Figure $2 \mathrm{a}$ and $\mathrm{c}$ ), while withdrawal from chronic treatment with $15 \mathrm{mg} / \mathrm{kg} /$ day PCP induced an elevation of brain reward thresholds that significantly lasted $6,12,24$, $72,96,120,144,168$, and $192 \mathrm{~h}$ compared to salinepretreated animals (Figure 2b). Further, there was an overall long-lasting and sustained elevation in brain reward thresholds in animals withdrawn from either 15 or $20 \mathrm{mg} /$ $\mathrm{kg} /$ day PCP compared to rats pretreated with $10 \mathrm{mg} / \mathrm{kg} /$ day PCP or saline that lasted during the entire month of testing, as indicated by the average threshold analysis $(\mathrm{F}(3,48)=4.11, p<0.05)$ (see Figure $2 \mathrm{~d}$ ). Parallel analyses of the response latency data showed that chronic administration of 15 and $20 \mathrm{mg} / \mathrm{kg} /$ day PCP significantly elevated the time to respond during the first 4 days of treatment compared to the latency of the $10 \mathrm{mg} / \mathrm{kg} / \mathrm{day}$ PCP or saline groups (Treatment effect: $\mathrm{F}(3,48)=3.85, p<0.05$; Time effect: $\mathrm{F}(13,624)=34.86, p<0.0001$; Treatment $\times$ Time interaction: $\mathrm{F}(39,624)=3.01, p<0.0001)$ (Figure 3a-c). After 

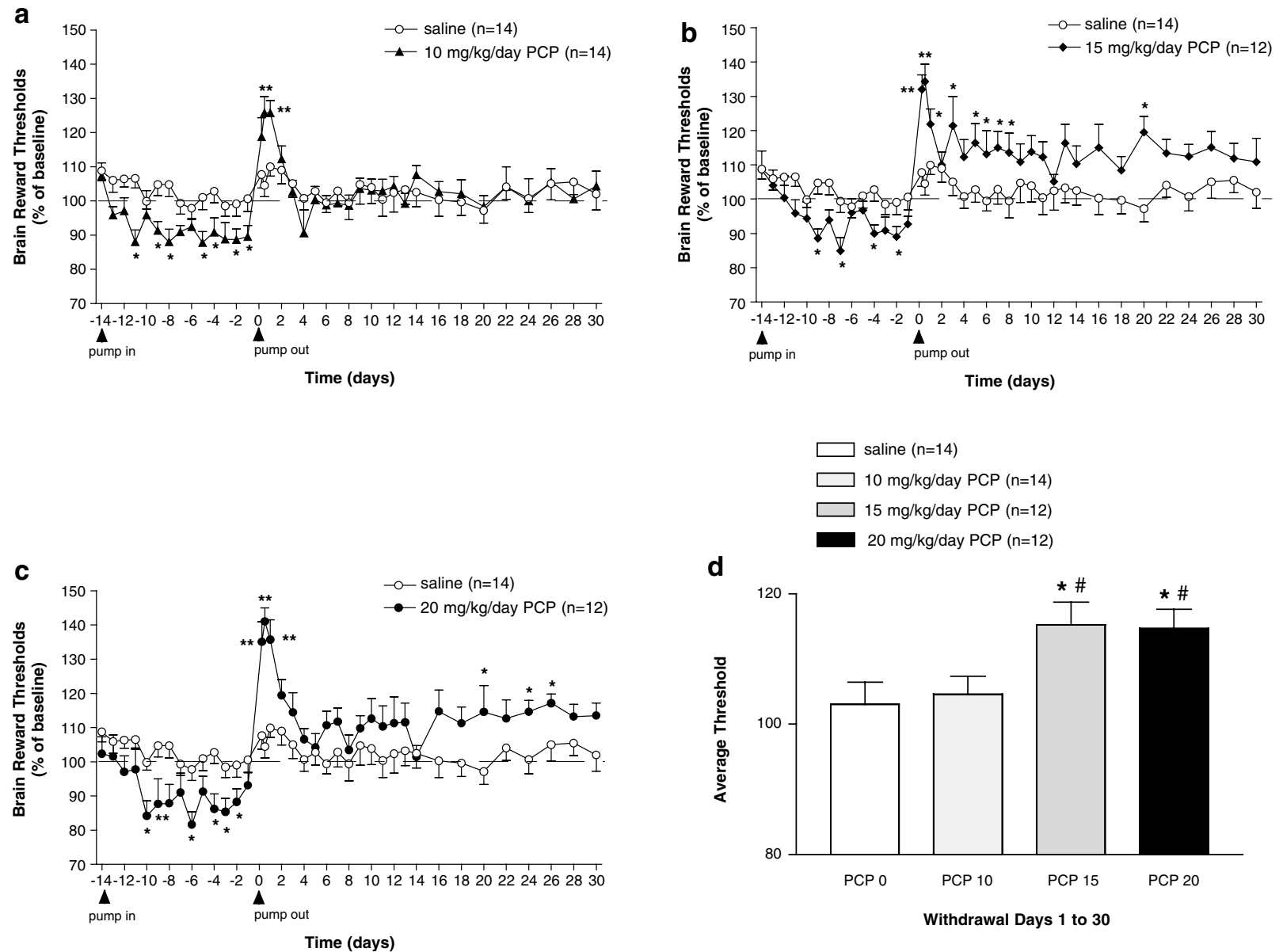

Figure 2 Mean brain reward thresholds ( \pm SEM) during chronic PCP administration and withdrawal. A I4-day exposure to I0 mg/kg/day (a), I5 mg/kg/ day (b), or $20 \mathrm{mg} / \mathrm{kg} /$ day (c) PCP via subcutaneous osmotic minipumps lowered brain reward thresholds compared to thresholds of saline-treated control animals; whereas withdrawal from the chronic drug treatment resulted in elevations in brain reward thresholds that lasted for the entire month of testing. (d) Persistent increase in brain reward thresholds over the 30-day period of withdrawal for animals previously treated with 15 and $20 \mathrm{mg} / \mathrm{kg} / \mathrm{day}$ PCP compared to thresholds of animals treated with $10 \mathrm{mg} / \mathrm{kg} /$ day PCP or saline. For comparison purposes, the same saline-treated control group data are shown in graphs (a)-(c). All original values were in microamperes. Asterisks indicate statistically significant differences between the thresholds of PCP and saline groups at specific time points ( $* p<0.05$ and $* * p<0.0$ I; Fisher's LSD post hoc test). The pound signs denote statistically significant differences from the I $0 \mathrm{mg} / \mathrm{kg} / \mathrm{day}$ PCP group ( $p<0.05$; Fisher's LSD post hoc test).

cessation of the treatment, there was a Treatment $\times$ Time interaction effect $(F(69,1104)=1.542, p<0.01)$. Nonetheless, analyses of the average response latency recorded during the month of withdrawal did not reveal any statistically significant differences between the four groups $(\mathrm{F}(3,48)=0.15, \mathrm{NS})$ (see Figure 3d).

\section{DISCUSSION}

The results showed that chronic sustained PCP exposure $(10,15$, or $20 \mathrm{mg} / \mathrm{kg} / \mathrm{day}$ administered chronically for a period of 14 days) led to a dose- and time-dependent lowering of brain reward thresholds reflecting reward facilitation. This action closely paralleled the development of tolerance to the stereotypy and ataxia induced by PCP (Sturgeon et al, 1982). It is however unlikely that the delayed onset of the effect of 15 and $20 \mathrm{mg} / \mathrm{kg} /$ day PCP on brain reward threshold was because of motoric disabilities as the rewarding effect of PCP emerged on the 5th day of treatment while response latencies returned to a baseline level only on the 8th day (see Figures $2 b, c, 3 b, c$ ), indicating that the effects of PCP on brain reward function and task performance were independent. By contrast, withdrawal from acute high PCP doses or from chronic sustained PCP exposure induced a decrease in brain reward function reflected in elevations in thresholds for electrical brain stimulation. Specifically, withdrawal from acute high PCP doses $(5$ and $10 \mathrm{mg} / \mathrm{kg}$ ) induced a diminution in brain stimulation reward that lasted $24 \mathrm{~h}$ and reflected a transient deficit in brain reward function. Withdrawal from chronic sustained PCP exposure gave rise to a very long-lasting elevation in brain reward threshold reflecting a deep depression in brain reward function that was much longer lasting than that seen from other drugs of abuse (see below), and lasted for at least a month. There were no large or consistent effects on the rats' response latencies during withdrawal, indicating that the performance of the ICSS task was not dramatically affected by the withdrawal from acute or chronic PCP treatment, and thus the effects on thresholds cannot be attributed to performance disabilities. 
a

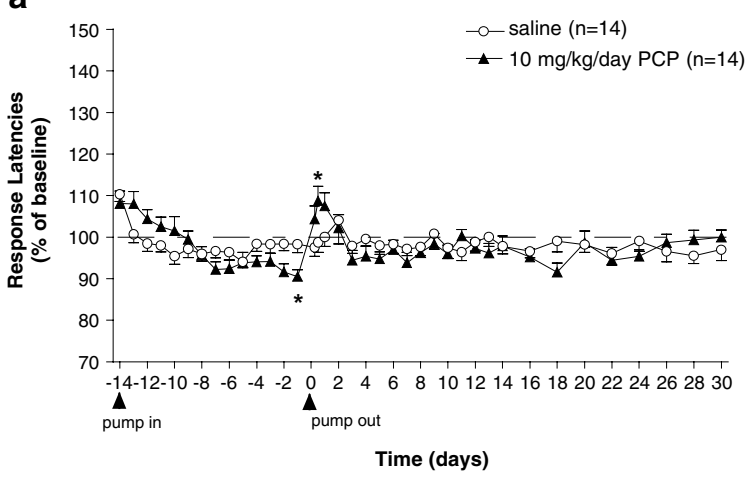

C

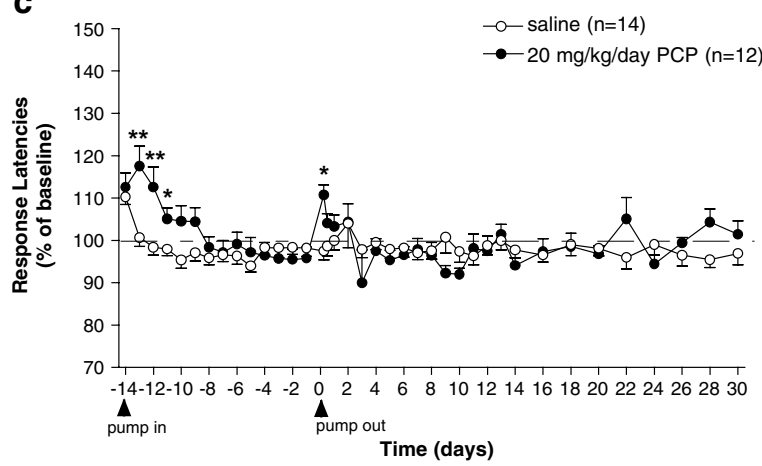

b

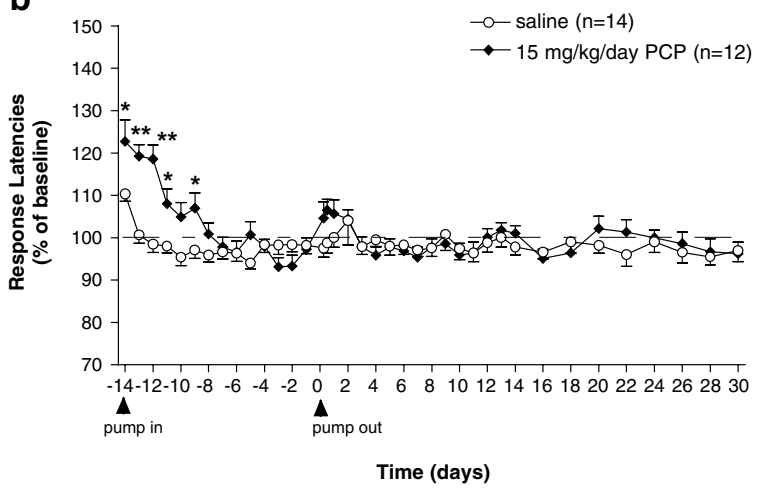

d

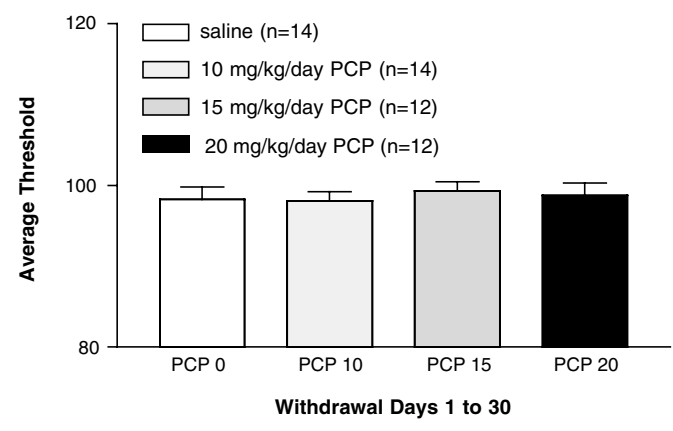

Figure 3 Mean response latencies ( \pm SEM) during chronic PCP administration and withdrawal. A I4-day exposure to $15 \mathrm{mg} / \mathrm{kg} / \mathrm{day}$ (b), or $20 \mathrm{mg} / \mathrm{kg} / \mathrm{day}$ (c) PCP via subcutaneous osmotic minipumps increased response latencies compared to latencies of animals treated with $10 \mathrm{mg} / \mathrm{kg} / \mathrm{day}$ PCP (a) or saline. Withdrawal from the chronic drug treatment resulted in a short-lasting increase in response latencies in the rats previously treated with $20 \mathrm{mg} / \mathrm{kg} / \mathrm{day} \mathrm{PCP}$ (c). There were no consistent changes in response latencies in the four groups of rats during the 30 days of withdrawal (d). For comparison purposes, the same saline-treated control group data are shown in graphs (a)-(c). All original values were in seconds. Asterisks indicate statistically significant differences between the PCP and saline groups at specific time points ( $p<0.05$ and $* * p<0.0$ l; Fisher's LSD post hoc test).

Interestingly, although the three doses of PCP $(10,15$, or $20 \mathrm{mg} / \mathrm{kg} /$ day) did not induce significantly different effects on brain reward thresholds during the chronic treatment, discontinuation of their administration affected brain reward threshold differentially over the month of observation. We observed an overall longer-lasting elevation in brain reward threshold in animals withdrawn from either 15 or $20 \mathrm{mg} / \mathrm{kg} /$ day PCP compared to rats treated with $10 \mathrm{mg} /$ $\mathrm{kg} /$ day PCP or saline that was indicative of an enduring depression in brain reward function. This 1-month duration is unusual compared to the 1- to 7-day effect seen in rats withdrawn from chronic amphetamine (eg Leith and Barrett, 1976; Kokkinidis and Zacharko, 1980; Kokkinidis et al, 1986; Lin et al, 1999; Paterson et al, 2000), cocaine (Markou and Koob, 1991, 1992a; Baldo et al, 1999), opiates (Schulteis et al, 1994), ethanol (Schulteis et al, 1995), and nicotine (Epping-Jordan et al, 1998; Harrison et al, 2001). Further, attempts to increase the duration of the effect of amphetamine and nicotine withdrawal on reward threshold using repeated withdrawal from continuous administration of these drugs were not successful (Paterson et al, 2000; Skjei and Markou, 2003). Interestingly, when nicotine was given for a prolonged period of time (ie $28 v s 7$ days via subcutaneous osmotic minipumps), rats exhibited a $14-15$ day elevation in brain reward threshold during the subsequent withdrawal that was independent of the dose administered (Skjei and Markou, 2003). Thus, it is hypothesized here that the duration of the chronic drug treatment is an important factor in determining the duration and magnitude of the brain reward deficit, and further investigation of this relation may offer new insights into the specificity of the neurobiological mechanisms underlying the enduring affective disturbances associated with long periods of drug use. Our present findings with PCP are consistent with data from other studies showing similar durable effects after cessation of chronic PCP treatment in cognitive function in monkeys or rats (Jentsch et al, 1997b, c), social withdrawal in mice (Quiao et al, 2001), and avolition in mice as reflected by increased immobility time in the forced-swim test (Noda et al, 1995, 2000).

One explanation for the prolonged manifestation of brain reward deficit observed after PCP administration discontinuation may be related to the opponent process theory. This theory postulates that the initial effects of the drug are opposed or counteracted by homeostatic changes in systems that mediate primary drug effects (Solomon and Corbit, 1974; Siegel, 1975). These neurobiological changes occur within the system that directly mediates the acute action of the drug or involve other systems that are recruited during chronic drug administration and are revealed at the cessation of the treatments (Koob and Le Moal, 1997). 
The early phase of the withdrawal may be hypothesized to be mediated by changes that take place within the primary system affected by the drug and the late phase by adaptations that occurred in other systems (Nestler and Aghajanian, 1997). In the present study, the dose-dependent increase in magnitude of the elevation in brain reward threshold observed during the first 2-3 days after cessation of chronic 10,15 , or $20 \mathrm{mg} / \mathrm{kg} /$ day PCP administration may be because of dose-dependent changes that developed in the primary system during the chronic drug treatment. Although these neurobiological changes seem to be transient only in rats withdrawn from $10 \mathrm{mg} / \mathrm{kg} /$ day PCP, it appears that the adaptations induced by 15 or $20 \mathrm{mg} / \mathrm{kg} /$ day PCP were more dramatic and triggered the involvement of other systems that together sustained the enduring expression of brain reward deficit shown in the present study.

In terms of the specific neurobiological mechanisms that may comprise these counteradaptations, data suggest alterations in the balance between serotonin and dopamine neurotransmission. PCP has complex biochemical actions. Other than being a noncompetitive antagonist of the NMDA receptor, PCP is also an inhibitor of serotonin and dopamine reuptake and affects gamma-aminobutyric acid (GABA) neuronal function (Smith et al, 1977; Gerhardt et $a l, 1987)$. It is generally assumed that the rewarding effects of acute or chronic PCP treatment are related to an increase in mesolimbic extracellular dopaminergic levels (Di Chiara and Imperato, 1988; Carboni et al, 1989) and a dosedependent progressive downregulation of $5-\mathrm{HT}_{2 \mathrm{~A}}$ receptors in response to the elevation in serotonin turnover produced by the drug (Nabeshima et al, 1985, 1987, 1996; Noda et al, 1998). Growing evidence indicates that PCP preferentially elevates dopaminergic transmission through its antagonist actions on NMDA receptors located on GABAegic inhibitory interneurons, thereby disinhibiting the firing of dopaminergic neurons, rather than through its action as a dopamine reuptake inhibitor (Jentsch et al, 1997a, 1998a). Nonetheless, although PCP treatment seems to have a common stimulatory action on serotonergic and dopaminergic neurotransmission, cessation of drug administration (ie withdrawal) leads to different actions in the two systems. It has been observed that withdrawal from PCP treatment is associated with an upregulation of $5-\mathrm{HT}_{2 \mathrm{~A}}$ receptors (Kitaichi et al, 1996, 1999) and a progressive increase in serotonin utilization in the prefrontal cortex, indicating an overstimulation of serotonin neurotransmission in this brain area during withdrawal; the amplitude of this effect is proportional to the duration of the preceding $\mathrm{PCP}$ treatment and is reversed by antipsychotic drugs having 5$\mathrm{HT}_{2 \mathrm{~A}}$ receptor antagonist activity (eg clozapine) (Noda et al, 1995, 2000; Quiao et al, 2001). Moreover, two laboratories showed that during PCP withdrawal, depending on the duration of PCP treatment, there is a progressive decrease in basal- or stress-evoked dopamine utilization in the prefrontal cortex associated with an increase in subcortical dopamine turnover induced by amphetamine or a stressor (Jentsch et al, 1997c, 1998b; Noda et al, 2000; Balla et al, 2001). Therefore, sustained PCP exposure seems to establish imbalances between serotonin and dopamine transmission in cortical brain regions as well as in the functioning of these two neurotransmitter systems between cortical and subcortical brain regions that may lead to the expression of a long-lasting dysphoric effect of the drug at the cessation of treatment.

Further emphasis has been put lately on the study of the induction by PCP of immediate-early genes that then would activate the expression of proteins intervening in the longlasting neurobiological changes underlying the enduring effects of PCP on behaviors, as observed here after cessation of chronic 15 or $20 \mathrm{mg} / \mathrm{kg} /$ day PCP treatment. It has been reported that PCP exerts complex time- and brain regiondependent effects on the expression of early genes such as $c$ fos, junB, zif268, and nerve growth factors that can be attenuated by the administration of antipsychotics or 5$\mathrm{HT}_{2 \mathrm{~A}}$ receptor antagonists (Nabeshima et al, 1996; Nakki et al, 1996; Gao et al, 1998; O’Neill et al, 1998). Of particular interest is the observation that $\mathrm{PCP}$, or its congener MK801, modulates the cAMP response element-binding protein (CREB) transcription factor family and the brain-derived neurotrophic factor (BDNF) (Castrén et al, 1993; Hughes et al, 1993; Storvik et al, 2000). CREB and BDNF have been studied for their transient and long-lasting, respectively, roles in the reinforcing effects of drugs (Horger et al, 1999; Nestler, 2001). Moreover, it has been recently revealed that within the mesolimbic dopaminergic system, activation of CREB is associated with the dysphoric effect of early cocaine withdrawal (Pliakas et al, 2001) and BDNF induces depression-like effects (Nestler et al, 2002). Therefore, these two proteins are promising candidates whose function may explain the short and enduring depressions in brain reward function observed in our study.

PCP-induced neurodegenerative changes in specific brain structures also have been described. Thus, one cannot exclude the possibility that the behavioral perturbations observed here with the chronic 15 or $20 \mathrm{mg} / \mathrm{kg} /$ day PCP treatment might be related to the neurotoxic effects of PCP. Acute bolus injection of high PCP doses $(50 \mathrm{mg} / \mathrm{kg})$ produced morphological changes involving a reversible vacuole reaction affecting cytoplasmic organelles in specific neurons of the posterior cingulate and retrosplenial cortex (Olney et al, 1999). Although the acute PCP doses used in the present study were not as high $(5$ and $10 \mathrm{mg} / \mathrm{kg}$ ), it is intriguing to note that the time of appearance of the vacuolizations (4-12 h; Olney et al, 1999) closely corresponds to the times at which elevations in brain reward threshold were observed after the acute PCP doses. Interestingly, the same authors and others reported that chronic PCP treatment over 3-14 days causes irreversible necrotic toxicity and apoptosis that spreads to many corticolimbic brain regions (eg the amygdala, dentate gyrus, entorhinal cortex, olfactory tubercle, and piriform cortex; Ellison and Switzer, 1993; Ellison, 1994; Corso et al, 1997; Johnson et al, 1998; Phillips et al, 2001; Sharp et al, 2001). These effects of PCP are blocked by antipsychotic drugs (Sharp et al, 1992; Johnson et al, 1998; Olney et al, 1999). No changes in absolute serotonin or dopamine concentrations have been reported with either acute or chronic treatment using high doses of PCP suggesting that there are no neurochemical lesions of these two important neurotransmitter innervations likely to be involved in the rewarding/ dysphoric actions of PCP (Jentsch et al, 1997b; Noda et al, 2000; Balla et al, 2001). Nevertheless, the irreversibility of the neurodegenerative and apoptotic actions of PCP 
observed in cortical and subcortical structures in which PCP acts to modulate neurotransmission may lead to the longlasting expression of the brain reward deficit observed during withdrawal from chronic high-dose PCP treatment.

Taking together the results from the literature summarized above and the present findings, it appears that withdrawal from acute or chronic PCP administration induces a negative affective state through modification of the functioning of numerous neurotransmitters and their related proteins in various cortical and subcortical brain regions. It is interesting to note that alterations in the function of dopamine and serotonin neurotransmission, the expression of immediate-early genes such as CREB and BDNF, or the induction of neuronal degeneration in cortical and subcortical areas also are reported during withdrawal from other drugs of abuse (Markou et al, 1998; Davidson et $a l, 2001)$, and are associated with nondrug-induced depressions (Nestler et al, 2002) and the negative symptoms of schizophrenia (Lipska et al, 2001). These observations, together with the fact that there is phenomenological resemblance in depressive symptoms seen in drug dependence, nondrug-induced depressions, and schizophrenia, support our hypothesis of overlapping neuronal mechanisms mediating a negative affective state that is common to these three disorders (Markou et al, 1998; Markou and Kenny, 2002). Moreover, considering that ICSS behavior was hypothesized to be mainly mediated by dopaminergic neurotransmission (Phillips and Fibiger, 1989; Stellar and Rice, 1989), our data together with those of Carlezon and Wise (1996b) clearly implicate a critical role for glutamatergic neurotransmission in ICSS behavior.

The present results may lead to further research that will offer new insights into the neurobiology mediating the negative affective aspects of drug dependence/withdrawal, depression, and schizophrenia. More specifically, the paradigm presented here appears to be a reliable procedure with which to investigate the interactions between dopaminergic and glutamatergic systems in modulating a state of anhedonia that has relevance to both core symptoms of drug-induced and nondrug-induced depressions and negative symptoms of schizophrenia. Especially, the mechanisms by which PCP induces expression of genes belonging to the cyclic adenosine monophosphate/protein kinase A/ dopamine- and adenosine-3,5-monophosphate-regulated phosphoprotein/protein phosphatase-1 (cAMP/PKA/ DARPP-32/PP-1) pathway, that is a crucial link between dopamine and glutamate receptor interrelations, would be of considerable interest in the study of the neurobiological changes underlying affective states. Overall, the present study suggests the potential utility of PCP as a pharmacological tool in the investigation of the correlates of anhedonia observed in drug dependence, depression, and schizophrenia.

In conclusion, blockade of NMDA receptors by PCP induced a deficit in brain reward function that may be analogous to the depressive-like symptoms observed in the symptomatology of PCP dependence/withdrawal, depression, and schizophrenia. As expected, withdrawal from chronic PCP treatment resulted in elevations of brain reward thresholds that are likely to be mediated at least in part by changes in neurotransmitter systems or gene expression, also implicated in the expression of withdrawal from other drugs of abuse. The present data also demonstrated a protracted and long-lasting depression in brain reward function after cessation of chronic administration of 15 or $20 \mathrm{mg} / \mathrm{kg} /$ day PCP. It is hypothesized that this sustained negative affective effect of PCP withdrawal induces behavioral and neurochemical changes with relevance to both drug- and nondrug-induced depressions and the negative symptoms of schizophrenia.

\section{ACKNOWLEDGMENTS}

This work was supported by the National Institute of Mental Health Grant MH 62527 and a Novartis Research Grant to AM. CS was a recipient of a fellowship from the Fondation pour la Recherche Medicale, Paris, France. We thank Dr Paul J Kenny for critical review of the manuscript, Ms Jessica Chevrette for technical assistance, and Mr Mike Arends for editorial assistance. This is publication number 14878-NP from The Scripps Research Institute.

\section{REFERENCES}

American Psychiatric Association (1994). Diagnostic and Statistical Manual of Mental Disorders, 4th edn. American Psychiatric Press: Washington, DC.

Baldo BA, Koob GF, Markou A (1999). Role of adenosine a2 receptors in brain stimulation reward under baseline conditions and during cocaine withdrawal in rats. J Neurosci 19: $11017-$ 11026.

Balla A, Koneru R, Smiley J, Sershen H, Javitt DC (2001). Continuous phencyclidine treatment induced schizophrenia-like hyperreactivity of striatal dopamine release. Neuropsychopharmacology 25: 157-164.

Barr GA, Paredes W, Bridger WH (1985). Place conditioning with morphine and phencyclidine: dose-dependent effects. Life Sci 36: 363-368.

Bespalov A, Lebedev A, Panchenko G, Zvartau E (1999). Effects of abused drugs on thresholds and breaking points of intracranial self-stimulation in rats. Eur Neuropsychopharmacol 9: 377-383.

Carboni E, Imperato A, Perezzani L, Di Chiara G (1989). Amphetamine, cocaine, phencyclidine and nomifensine increase extracellular dopamine concentrations preferentially in the nucleus accumbens of freely moving rats. Neuroscience 28: 653-661.

Carlezon Jr WA, Wise RA (1993). Phencyclidine-induced potentiation of brain stimulation reward: acute effects are not altered by repeated administration. Psychopharmacology 111: 402-408.

Carlezon Jr WA, Wise RA (1996a). Microinjections of phencyclidine (PCP) and related drugs into nucleus accumbens shell potentiate medial forebrain bundle brain stimulation reward. Psychopharmacology 128: 413-420.

Carlezon Jr WA, Wise RA (1996b). Rewarding actions of phencyclidine and related drugs in nucleus accumbens shell and frontal cortex. J Neurosci 16: 3112-3122.

Carlsson A, Waters N, Holm-Waters S, Tedroff J, Nilsson M, Carlsson ML (2001). Interactions between monoamines, glutamate, and GABA in schizophrenia: new evidence. Ann Rev Pharmacol Toxicol 41: 237-260.

Castrén E, da Penha Berzaghi M, Lindholm D, Thoenen H (1993). Differential effects of MK-801 on brain-derived neurotrophic factor mRNA levels in different regions of the rat brain. Exp Neurol 122: 244-252. 
Collins RJ, Weeks JR, Cooper MM, Good PI, Russell RR (1984). Prediction of abuse liability of drugs using intravenous selfadministration by rats. Psychopharmacology 82: 6-13.

Corso TD, Sesma MA, Tenkova TI, Der TC, Wozniak DF, Farber NB et al (1997). Multifocal brain damage induced by phencyclidine is augmented by pilocarpine. Brain Res 752: 1-14.

Crider R (1986). Phencyclidine: changing abuse patterns. NIDA Res Monograms 64: 163-173.

Davidson C, Gow AJ, Lee TH, Ellinwood EH (2001). Methamphetamine neurotoxicity: necrotic and apoptotic mechanisms and relevance to human abuse and treatment. Brain Res Rev 36: 1-22.

Di Chiara G, Imperato A (1988). Drugs abused by humans preferentially increase synaptic dopamine concentrations in the mesolimbic system of freely moving rats. Proc Natl Acad Sci USA 85: $5274-5278$.

Ellison G (1994). Competitive and noncompetitive NMDA antagonists induce similar limbic degeneration. Neuroreport 5: 2688-2692.

Ellison G, Switzer RC (1993). Dissimilar patterns of degeneration in brain following four different addictive stimulants. Neuroreport 5: $17-20$.

Engen T (1971). Psychophysics. In: Kling JW, Riggs LA (eds). Woodworth and Schlosberg's Experimental Psychology, 3rd edn. Holt, Rinehart and Winston: New York. pp 11-46.

Epping-Jordan MP, Watkins SS, Koob GF, Markou A (1998). Dramatic decrease in brain reward function during nicotine withdrawal. Nature 393: 76-79.

Fram DH, Stone N (1986). Clinical observations in the treatment of adolescent and young adult PCP abusers. NIDA Res Monograms 64: 252-261.

Gao XM, Hashimoto T, Tamminga CA (1998). Phencyclidine (PCP) and dizocilpine (MK-801) exert time-dependent effects on the expression of immediate early genes in rat brain. Synapse 29: $14-28$.

Gerhardt GA, Pang K, Rose GM (1987). In vivo electrochemical demonstration of the presynaptic actions of phencyclidine in rat caudate nucleus. J Pharmacol Exp Ther 241: 714-721.

Geyer MA, Markou A (1995). Animal models of psychiatric disorders. In: Bloom FE, Kupfer DJ (eds). Psychopharmacology: The Fourth Generation of Progress. Raven Press: New York. pp 787-798.

Glick SD, Weaver LM, Meibach RC (1980). Lateralization of reward in rats: differences in reinforcing thresholds. Science 207: 10931095.

Harrison AA, Liem TB, Markou A (2001). Fluoxetine combined with a serotonin-1A receptor antagonist reversed reward deficits observed during nicotine and amphetamine withdrawal in rats. Neuropsychopharmacology 25: 55-71.

Horger BA, Lyasere CA, Berhow MT, Messer CJ, Nestler EJ, Taylor JR (1999). Enhancement of locomotor activity and conditioned reward cocaine by brain-derived neurotrophic factor. J Neurosci 19: $4110-4122$.

Hughes P, Dragunow M, Beilharz E, Lawlor P, Gluckman P (1993). MK-801 induces immediate-early gene proteins and BDNF mRNA in rat cerebrocortical neurones. Neuroreport 4: 183-186.

Iwamoto ET (1986). Place-aversion conditioned by phencyclidine in rats: development of tolerance and pharmacological antagonism. Alcohol Drug Res 6: 265-276.

Javitt DC, Zukin SR (1991). Recent advances in the phencyclidine model of schizophrenia. Am J Psychiatry 148: 1301.

Jentsch JD, Elsworth JD, Redmond Jr DE, Roth RH (1997a). Phencyclidine increases forebrain monoamine metabolism in rats and monkeys: modulation by isomers of HA966. J Neurosci 17: $1769-1775$.

Jentsch JD, Redmond DE, Elsworth JD, Taylor JR, Youngren KD, Roth RH (1997b). Enduring cognitive deficits and cortical dopamine dysfunction in monkeys after long-term administration of phencyclidine. Science 277: 953-955.
Jentsch JD, Roth RH (1999). The neuropsychopharmacology of phencyclidine: from NMDA receptor hypofunction to the dopamine hypothesis of schizophrenia. Neuropsychopharmacology 20: 201-225.

Jentsch JD, Taylor JR, Roth RH (1998b). Subchronic phencyclidine administration increases mesolimbic dopaminergic system responsivity and augments stress- and psychostimulant-induced hyperlocomotion. Neuropsychopharmacology 19: 105-113.

Jentsch JD, Tran A, Dung LE, Youngren KD, Roth RH (1997c). Subchronic phencyclidine administration reduces mesoprefrontal dopamine utilization and impairs prefrontal cortical-dependent cognition in the rat. Neuropsychopharmacology 17: 92-99.

Jentsch JD, Tran A, Taylor JR, Roth RH (1998a). Prefrontal cortical involvement in phencyclidine-induced activation of the mesolimbic dopamine system: behavioral and neurochemical evidence. Psychopharmacology 138: 89-95.

Johnson KM, Phillips M, Wang C, Kevetter GA (1998). Chronic phencyclidine induces behavioral sensitization and apoptotic cell death in the olfactory and piriform cortex. J Neurosci Res 52: 709-722.

Kitaichi K, Noda Y, Hasegawa T, Furukawa H, Nabeshima T (1996). Acute phencyclidine induces aversion, but repeated phencyclidine induces preference in the place conditioning test in rats. Eur J Pharmacol 318: 7-9.

Kitaichi K, Noda Y, Miyamoto Y, Numaguchi A, Osawa H, Hasegawa $\mathrm{T}$ et al (1999). Involvement of the serotonergic neuronal system in phencyclidine-induced place aversion in rats. Behav Brain Res 103: 105-111.

Kokkinidis L, Zacharko RM (1980). Enhanced lateral hypothalamic self-stimulation responding after chronic exposure to amphetamine. Behav Neural Biol 29: 493-497.

Kokkinidis L, Zacharko RM, Anisman H (1986). Amphetamine withdrawal: a behavioral evaluation. Life Sci 38: 1617-1623.

Koob GF, Le Moal M (1997). Drug abuse: hedonic homeostatic dysregulation. Science 278: 52-58.

Kornetsky C, Esposito R, Mc Lean S, Jacobson JO (1979). Intracranial self-stimulation thresholds. Arch Gen Psychiatry 36: 289-292.

Kornetsky C, Markowitz RA, Esposito RU (1981). Phencyclidine and naloxone: effects on sensitivity to aversive and rewarding stimulation in the rat. In: Domino EF (ed). PCP (Phencyclidine): Historical and Current Perspectives. NPP books: Ann Arbor, MI. pp 321-330.

Kuhar MJ, Baja JW, Cone EJ (1990). Phencyclidine binding to striatal receptors. Neuropharmacology 29: 295-297.

Leith NJ, Barrett RJ (1976). Amphetamine and the reward system: evidence for tolerance and post-drug depression. Psychopharmacology 46: 19.

Lin D, Koob GF, Markou A (1999). Differential effects of withdrawal from chronic amphetamine or fluoxetine administration on brain stimulation reward in the rat-Interactions between the two drugs. Psychopharmacology 145: 283-294.

Lipska BK, Khaing ZZ, Weickert CS, Weinberger DR (2001). BDNF mRNA expression in rat hippocampus and prefrontal cortex: effects of neonatal ventral hippocampal damage and antipsychotic drugs. Eur J Neurosci 14: 135-144.

Markou A, Frank RA (1987). The effect of operant and electrode placement on self-stimulation train duration response functions. Physiol Behav 41: 303-308.

Markou A, Kenny JP (2002). Neuroadaptations to chronic exposure to drugs of abuse: Relevance to depressive symptomatology seen across psychiatric diagnostic categories. Neurotoxicity Res 4: 297-313.

Markou A, Koob GF (1991). Postcocaine anhedonia: an animal model of cocaine withdrawal. Neuropsychopharmacology 4: $17-26$.

Markou A, Koob GF (1992a). Bromocriptine reverses the elevation in intracranial self-stimulation thresholds observed in a rat 
model of cocaine withdrawal. Neuropsychopharmacology 7: 213224.

Markou A, Koob GF (1992b). Construct validity of a selfstimulation threshold paradigm: effects of reward and performance manipulations. Physiol Behav 51: 111-119.

Markou A, Koob GF (1993). Intracranial self-stimulation threshold as a measure of reward. In: Sagal A (ed). Behavioural Neuroscience: A Practical Approach. Oxford University Press: New York. pp 93-115.

Markou A, Kosten TR, Koob GF (1998). Neurobiological similarities in depression and drug-dependence: a self-medication hypothesis. Neuropsychopharmacology 18: 135-174.

Nabeshima T, Fukaya H, Yamaguchi K, Ishikawa K, Furukawa H, Kameyama T (1987). Development of tolerance and supersensitivity to phencyclidine in rats after repeated administration of phencyclidine. Eur J Pharmacol 135: 23-33.

Nabeshima T, Kitaichi K, Noda Y (1996). Functional changes in neuronal systems induced by phencyclidine administration. Ann NY Acad Sci 801: 29-38.

Nabeshima T, Noda Y, Yamaguchi K, Ishikawa K, Furukawa H, Kameyama T (1985). Acute and chronic phencyclidine changes serotonin receptors in rat brain. Eur J Pharmacol 109: 129-132.

Nakki R, Sharp FR, Sagar SM, Honkaniemi J (1996). Effects of phencyclidine on immediate early gene expression in the brain. $J$ Neurosci Res 45: 13-27.

Nestler EJ (2001). Molecular basis of long-term plasticity underlying addiction. Nat Rev Neurosci 2: 119-128.

Nestler EJ, Aghajanian GK (1997). Molecular and cellular basis of addiction. Science 278: 58-63.

Nestler EJ, Barrot M, Di Leone RJ, Eisch AJ, Gold SJ, Monteggia LM (2002). Neurobiology of depression. Neuron 34: 13-25.

Noda Y, Kamei H, Mamiya T, Furukawa H, Nabeshima T (2000). Repeated phencyclidine treatment induces negative symptomlike behavior in forced swimming test in mice: imbalance of prefrontal serotonergic and dopaminergic functions. Neuropsychopharmacology 23: 375-387.

Noda Y, Miyamoto Y, Takayoshi M, Kamei H, Furukawa H, Nabeshima T (1998). Involvement of dopaminergic system in phencyclidine-induced place preference in mice pretreated with phencyclidine repeatedly. J Pharmacol Exp Ther 286: 44-51.

Noda Y, Yamada K, Furukawa H, Nabeshima T (1995). Enhancement of immobility in a forced swimming test by subacute or repeated treatment with phencyclidine: a new model of schizophrenia. Br J Pharmacol 116: 2531-2537.

Olney JW, Newcomer JW, Farber NB (1999). NMDA receptor hypofunction model of schizophrenia. J Psychiat Res 33: 523-533.

O'Neill MF, Hicks CA, Shaw G, Parameswaran T, Cardwell GP, O'Neill MJ (1998). Effects of 5-hydroxytryptamine2 receptor antagonism on the behavioral activation and immediate early gene expression induced by dizocilpine. J Pharmacol Exp Ther 287: 839-846.

Paterson NE, Myers C, Markou A (2000). Effects of repeated withdrawal from continuous amphetamine administration on brain reward function in rats. Psychopharmacology 152: 440.

Pellegrino LJ, Pellegrino AS, Cushman AJ (1979). A Stereotaxic Atlas of the Rat Brain, 2nd edn. Plenum Press: New York.

Phillips AG, Fibiger HC (1989). Neuroanatomical bases of ICSS - untying the Gordian knot. In: Liebman JM, Cooper SJ (eds). The Neuropharmacological Basis of Reward. Oxford University Press: New York. pp 66-105.

Phillips M, Wang C, Johnson KM (2001). Pharmacological characterization of locomotor sensitization induced by chronic phencyclidine administration. J Pharmacol Exp Ther 296: 905-913.
Pliakas AM, Carlson RR, Neve RL, Kondari C, Nestler EJ, Carlezon Jr WA (2001). Altered responsiveness to cocaine and increased immobility in the forced swim test associated with elevated cAMP response element-binding expression in nucleus accumbens. J Neurosci 21: 7397-7403.

Quiao H, Noda Y, Kamei H, Nagai T, Furukawa H, Miura H et al (2001). Clozapine, but not haloperidol, reverses social behavior deficit in mice during withdrawal from chronic phencyclidine treatment. Neuroreport 12: 11-15.

Rothman RB, Reid AA, Monn JA, Jacobson AE, Rice KC (1989). The psychotomimetic drug phencyclidine labels two high affinity binding sites in guinea pig brain: evidence for $N$-methyl-Daspartate-coupled and dopaminergic reuptake carrier-associated phencyclidine binding sites. Mol Pharmacol 36: 887-896.

Schaefer GJ, Michael RP (1990). Interactions of naloxone with morphine, amphetamine and phencyclidine on fixed interval responding for intracranial self-stimulation in rats. Psychopharmacology 102: 263-268.

Schroeder U, Schroeder H, Darius J, Grecksch G, Sabel AA (1998). Simulation of psychosis by continuous delivery of phencyclidine from controlled-release polymer implants. Behav Brain Res 97: 59-68.

Schulteis G, Markou A, Cole M, Koob GF (1995). Decreased brain reward produced by ethanol withdrawal. Proc Natl Acad Sci USA 92: $5880-5884$.

Schulteis G, Markou A, Gold LH, Stinus L, Koob GF (1994). Relative sensitivity to naloxone of multiple indices of opiate withdrawal: a quantitative dose-reponse analysis. J Pharmacol Exp Ther 271: 1391.

Sharp FR, Butman M, Wang S, Koistinaho J, Graham SH, Sagar SM et al (1992). Haloperidol prevents induction of the hsp70 heat shock gene in neurons injured by phencyclidine (PCP), MK801, and ketamine. J Neurosci Res 33: 605-616.

Sharp FR, Tomitaka M, Bernaudin M, Tomitaka S (2001). Psychosis: pathological activation of limbic thalamocortical circuits by psychomimetics and schizophrenia. Trends Neurosci 24: $330-334$.

Siegel S (1975). Evidence from rats that morphine tolerance is a learned response. J Comp Physiol Psychol 89: 498-506.

Skjei KL, Markou A (2003). Effects of repeated withdrawal episodes, nicotine dose, and duration of nicotine exposure on the severity and duration of nicotine withdrawal in rats. Psychopharmacol, in press.

Smith RC, Meltzer HY, Arora RC, Davis JM (1977). Effects of phencyclidine on $[3 \mathrm{H}]$ catecholamine and $[3 \mathrm{H}]$ serotonin uptake in synaptosomal preparations from rat brain. Biochem Pharmacol 26: 1435-1439.

Solomon RL, Corbit JD (1974). An opponent-process theory of motivation. Psychol Rev 81: 119-145.

Stellar JR, Rice MB (1989). Pharmacological basis of ICSS reward. In: Liebman JM, Cooper SJ (eds). The Neuropharmacological Basis of Reward. Oxford University Press: New York. pp 14-65.

Storvik M, Lindén A-M, Kontkanen O, Lakso M, Castrén E, Wong $\mathrm{G}$ (2000). Induction of cAMP response element modulator (CREM) and inducible cAMP early repressor (ICER) expression in rat brain by uncompetitive $N$-methyl-D-aspartate receptor antagonists. J Pharmacol Exp Ther 294: 52-60.

Sturgeon RD, Fessler RG, London SF, Meltzer HY (1982). Behavioral effects of chronic phencyclidine administration in rats. Psychopharmacology 76: 52-56.

Wise RA (1989). The brain and reward. In: Liebman JM, Cooper SJ (eds). The Neuropharmacological Basis of Reward. Oxford University Press: Oxford. pp 377-424.

Wise RA, Bauco P, Carlezon Jr WA (1992). Self-stimulation and drug reward mechanisms. Ann NY Acad Sci 654: 192-198. 